\title{
Decreased Incidence of Michigan Emergency Department Visits for Febrile Neutropenia Observed After Public Health Measures for the COVID-19 Pandemic
}

\author{
Michael Baracy \\ Ascension St. John \\ Karen Hagglund \\ Ascension St. John \\ Logan Corey ( $\sim$ loganscorey@gmail.com ) \\ Wayne State University
}

\section{Short Report}

Keywords: Febrile neutropenia, masking, social distancing, Hematologic malignancy

Posted Date: December 29th, 2021

DOI: https://doi.org/10.21203/rs.3.rs-1214294/v1

License: (c) (1) This work is licensed under a Creative Commons Attribution 4.0 International License.

Read Full License 


\section{Abstract}

Importance: Masking and social distancing appear to decrease the of febrile neutropenia in susceptible populations, especially among patients with hematologic malignancies.

Objective: To determine whether COVID-19 infection mitigation efforts, namely masking and social distancing, results in a reduction in the incidence of febrile neutropenia.

Design: This was a retrospective cohort study comparing the incidence of $\mathrm{FN}$ in the 13 months prior to (Year 0 ) and 13 months following (Year 1) the public health executive orders (PHEO) in Michigan. Data voluntarily submitted by Michigan emergency departments to the National Syndromic Surveillance Program (NSSP) was queried for all ED visits from April 1st, 2019 to March 31st, 2021.

Setting: Population based study.

Participants: A population-based sample of patients who reported to a Michigan emergency department and on whom data was captured.

Intervention(s): Population based masking and social distancing.

Main Outcome(s) and Measure(s): The primary study outcome was the incidence of FN as a proportion of emergency visits in the 13-months before and after COVID-19 mitigations efforts, namely masking and social distancing. We hypothesized that there would be a significant decrease in the incidence of FN in the period following the public health executive orders aimed at reducing the spread of the COVID-19 virus.

Results: There was a total of 8,979,221 total ED visits captured during the study period. In Year 0 there were $5,073,081$ recorded ED visits and 3,906,140 in Year 1, a decrease of $23 \%$. There was a significant reduction in the proportion of total ED visits with a diagnosis of $\mathrm{FN}$, decreasing $13.3 \%$ across periods $(0.15 \%$ vs. $0.13 \%, p=0.036)$. In patients with a hematologic malignancy the incidence of FN was significantly lower in the period following PHEO (22\% vs $17 \%$, $\mathbf{p}=\mathbf{0 . 0 2}$, Table 2$)$.

Conclusions and Relevance: Our study found a significant association between social distancing and mask guidelines implemented on a large public scale with decreased rates of FN, particularly in those with a hematologic malignancy. These findings may be useful in the design of clinical trials as well as informing future recommendations for the prevention of $\mathrm{FN}$.

\section{Key Points}

\section{Question:}

Did public health interventions implemented to prevent the spread of COVID-19 in Michigan also affect the incidence of Febrile Neutropenia in Michigan? 


\section{Findings:}

This was a retrospective cohort study that found a significant reduction in the incidence of febrile neutropenia in the 13 months following the implementation of public health interventions compared to the prior 13 months - a decrease of approximately $13 \%$.

\section{Meaning:}

Social distancing and masking may decrease risk of febrile neutropenia in susceptible populations.

\section{Introduction}

Febrile neutropenia (FN) is defined as neutropenia in the setting of a temperature greater than or equal to 100.4 degrees Fahrenheit and is one of the most common and costly complications associated with cancer treatment ${ }^{1,2}$. Granulocyte colony stimulating factor (GCSF) is the most effective prophylaxis against neutropenia and the subsequent development of $\mathrm{FN}^{3,4}$. However, little is known about nonpharmacological prevention strategies for $\mathrm{FN}$ in at-risk populations.

Currently, FN prevention strategies include hand hygiene and the avoidance of sick contacts and crowds, however the impact of these efforts is unknown ${ }^{5}$. Furthermore, most patients with FN and culture-proven bacteremia are thought to have acquired it by translocation of gut bacteria ${ }^{6}$. We are unaware of any population-based studies evaluating the impact of widespread public health interventions on the incidence of FN.

The public health crisis due to COVID-19 and its corresponding public health interventions provided a unique opportunity to evaluate the impact of social distancing and masking on the incidence of FN. In March of 2020, the state of Michigan issued an Executive Order that urged residents to remain at home and socially distanced whenever feasible, which was addended shortly thereafter to include a mask mandate ${ }^{7}$. The aim of our study was to evaluate the association of these mitigation efforts and the incidence of FN in patients presenting to emergency departments (EDs) in the state of Michigan.

\section{Methods, Data Collection, And Coding}

This is a retrospective cohort study comparing the incidence of FN in the 13 months prior to (Year 0 , March 1, 2019 - March 31, 2020) and the 13 months following (Year 1, April 1, 2020 - April 31, 2021) the public health executive orders (PHEO) in Michigan. Approximately $89 \%$ of EDs across Michigan voluntarily submit encounter data (patient's chief complaint, associated diagnoses, age, sex, intake temperature, intake percent oxygen saturation, and blood pressure) to the National Syndromic Surveillance Program (NSSP). It was queried for all encounters with a diagnosis of Neutropenia (ICD-10CM D70) from March 1, 2019 - April 31, 2021. Febrile neutropenia was defined as an intake temperature greater than or equal to 100.4 degrees Fahrenheit and an ICD-10-CM D70. The incidence of FN in Year 0 was compared to the incidence of FN in Year 1. To account for the impact of the COVID-19 pandemic on 
total ED visits, the incidence of each ICD code was analyzed as a proportion of ED visits for the corresponding year. Associated ICD-10-CM codes were grouped according to Clinically Relevant Groups (CRG) (Supplementary Table 1), modified from the Healthcare Cost and Utilization Project ${ }^{8}$. Analysis of incidence of $\mathrm{FN}$ in each CRG was also performed. A visit containing multiple ICD-10-CM diagnostic codes was included in multiple CRGs, if applicable. This study was deemed exempt by the responsible institutional review board.

\section{Statistical Analysis}

Descriptive statistics were generated to characterize the study cohorts. Continuous variables are described as the mean with standard deviation or median with range or interquartile range. Categorical variables are described as frequency distributions. Univariable analysis of factors associated with FN were assessed using Student's t-test, analysis of variance, and the chi-squared analysis. Multivariable analysis was done using logistic regression. Analyses were conducted using SPSS version 25.0 and a pvalue less than 0.05 was considered statistically significant.

\section{Results}

From March 1st, 2019 to April 31st, 2021 there were 8,979,221 total ED visits in the state of Michigan that had data submitted to the NSSP with at least one viable ICD-10 code. In Year 0, there were 5,073,081 recorded ED visits and 3,906,140 in Year 1, a decrease of 23\%. There was a total of 5,717 encounters with a diagnosis consistent with neutropenia. The proportion of neutropenic patients with a diagnosis of FN presenting to ED did not change significantly before and after PHEO ( $23 \%$ vs $21 \%, p=0.09)$. There was, however, a significant reduction in the proportion of total ED visits with a diagnosis of FN, decreasing $13.3 \%$ from Year 0 to Year 1 ( $0.15 \%$ vs. $0.13 \%, p=0.036)$.

In a sub-analysis of all patients with $\mathrm{FN}$, the proportion of patients with $\mathrm{FN}$ and associated diagnosis of hematologic malignancy was significantly lower in the period following PHEO as well ( $22 \%$ vs $17 \%$, $\mathbf{p}=\mathbf{0 . 0 2}$, Table 2b). In Year 0 there was a $29.3 \%$ incidence of $F N$ in neutropenic patients with a CRG of hematologic malignancy, versus a $21.2 \%$ incidence in neutropenic patients without a CRG of hematologic malignancy ( $\mathbf{p}<0.0001$, Figure 1B). This difference was not observed in Year $1(23.8 \%$ vs $20.2 \%, p=0.12)$. Hematologic malignancy was the only CRG diagnosis to have a relatively higher rate of FN in Year 0 compared to Year 1.

\section{Discussion}

The public health response to COVID-19 in the state of Michigan provided a unique opportunity to analyze the impact of social distancing and masking on FN. Masking and social distancing designed to prevent the spread of COVID-19 have resulted in the decline of other non-covid viral illnesses ${ }^{9,10}$. Our study is the first to document an association between this phenomenon and a decline in rates of FN, both overall and in patients with an ICD-10-CM diagnosis consistent with hematologic malignancy. 
In the majority of cases, the underlying cause of FN is unknown, and therefore little is known about the efficacy of non-pharmacological efforts to prevent development of FN in neutropenic patients ${ }^{11}$. Our study is the first to report an association between implementation of public health measures to prevent the spread of communicable diseases and a significant reduction in cases of $\mathrm{FN}$ associated with hematologic malignancies ( $22 \%$ vs $17 \%, p=0.02$ ). This is an important finding as patients with hematologic cancers are particularly vulnerable to $\mathrm{FN}$ and its associated morbidity and mortality ${ }^{12}$.

\section{Strengths And Limitation}

This study's strengths include the large number of encounters and associated accurate objective data points (ICD codes and temperature). Additionally, Michigan adopted the stay-at-home orders and mask mandates quickly and broadly, with one of the highest compliance rates of the country during Year 1 (Supplemental Figure 1) ${ }^{13}$. As a result, we were likely able to accurately assess the effect of COVID-19 mitigation efforts on $\mathrm{FN}$.

Our study has several limitations in addition to the inherent vulnerability to unmeasured biases found in retrospective studies: 1) There may be a small number of encounters of FN that are missed in this dataset; 2) Only the intake vital signs were available, and a temperature of $100.4^{\circ} \mathrm{F}$ was selected as the cutoff for diagnosing FN (rather than $101^{\circ} \mathrm{F}$ ) in an effort to have a more inclusive cohort; 3) Each ED visit was treated as a separate encounter. Therefore, a patient with FN who presented to the ED on multiple occasions would be captured multiple times; 4) It is impossible to account for individual patient hesitancy on presenting to $\mathrm{ED}^{14}$; 5) Charts review was not possible, so the effect of active myelosuppressive therapy could not be assessed; 6) The number and identify of facilities contributing data changes over time, and the use of diagnosis codes could be inconsistent across and within facilities.

\section{Conclusion}

Our study found a significant association between the implementation of social distancing and mask guidelines, and a decreased rate of FN in ED patients with neutropenia. This reduction was most pronounced in those with an associated diagnosis of hematologic malignancy. These findings may be useful in the design of clinical trials as well as informing future recommendations for the prevention of febrile neutropenia.

\section{Declarations}

Declaration of Interests: All authors have no conflicts of interest to declare.

\section{Acknowledgements:}


We would like to acknowledge the following staff from the MDHHS for their help in data collection and management, especially Justin Henderson.

\section{References}

1. Lyman, Gary H., Shannon L. Michels, Matthew W. Reynolds, Rich Barron, Karen Smoyer Tomic, and Jingbo Yu. 2010. "Risk of Mortality in Patients with Cancer Who Experience Febrile Neutropenia." Cancer116 (23): 5555-63.

2. Tai, Eric, Gery P. Guy, Angela Dunbar, and Lisa C. Richardson. 2017. "Cost of Cancer-Related Neutropenia or Fever Hospitalizations, United States, 2012." Journal of Oncology Practice / American Society of Clinical Oncology 13 (6): e552-61.

3. Averin, Ahuva, Amanda Silvia, Lois Lamerato, Kathryn Richert-Boe, Manpreet Kaur, Devi Sundaresan, Neel Shah, et al. 2021. "Risk of Chemotherapy-Induced Febrile Neutropenia in Patients with Metastatic Cancer Not Receiving Granulocyte Colony-Stimulating Factor Prophylaxis in US Clinical Practice." Supportive Care in Cancer: Official Journal of the Multinational Association of Supportive Care in Cancer 29 (4): 2179-86.

4. Mhaskar, Rahul, Otavio Augusto Camara Clark, Gary Lyman, Tobias Engel Ayer Botrel, Luciano Morganti Paladini, and Benjamin Djulbegovic. 2014. "Colony-Stimulating Factors for ChemotherapyInduced Febrile Neutropenia." Cochrane Database of Systematic Reviews, no. 10 (October): CD003039.

5. CDCBreastCancer. 2021. "Information for Patients and Caregivers." July 13, 2021. https://www.cdc.gov/cancer/preventinfections/patients.htm.

6. Zimmer, Andrea J., and Alison G. Freifeld. 2019. "Optimal Management of Neutropenic Fever in Patients With Cancer." Journal of Oncology Practice / American Society of Clinical Oncology 15 (1): 19-24.

7. “Executive Order 2020-153: Masks." n.d. Accessed June 5, 2021. https://www.michigan.gov/whitmer/0,9309,7-387-90499_90705-535105--00.html.

8. “Clinical Classifications Software Refined (CCSR)." n.d. Accessed June 5, 2021. https://www.hcupus.ahrq.gov/toolssoftware/ccsr/ccs_refined.jsp.

9. Dezman, Zachary D. W., Benoit Stryckman, Kori S. Zachrison, Ryan M. Conrad, David Marcozzi, Laura Pimentel, Margaret Samuels-Kalow, and Charles B. Cairns. 2021. "Masking for COVID-19 Is Associated with Decreased Emergency Department Utilization for Non-COVID Viral Illnesses and Respiratory Conditions in Maryland." The American Journal of Medicine, July. https://doi.org/10.1016/j.amjmed.2021.06.008.

10. Chu, D. K., E. A. Akl, S. Duda, K. Solo, and S. Yaacoub. 2020. "Physical Distancing,Face Masks, and Eye Protection to Prevent Person-to-Person Transmission of SARS-CoV-2 and COVID-19: A Systematic Review and Meta ... The Lancet. https://www.sciencedirect.com/science/article/pii/S0140673620311429. 
11. Pizzo, Philip A. 2019. "Management of Patients With Fever and Neutropenia Through the Arc of Time: A Narrative Review." Annals of Internal Medicine 170 (6): 389-97.

12. Kuderer, Nicole M., David C. Dale, Jeffrey Crawford, Leon E. Cosler, and Gary H. Lyman. 2006. "Mortality, Morbidity, and Cost Associated with Febrile Neutropenia in Adult Cancer Patients." Cancer 106 (10): 2258-66.

13. "IHME." n.d. Accessed September 6, 2021. https://covid19.healthdata.org/united-states-ofamerica/michigan?view=mask-use\&tab=trend.

14. Hartnett, Kathleen P., Aaron Kite-Powell, Jourdan DeVies, Michael A. Coletta, Tegan K. Boehmer, Jennifer Adjemian, Adi V. Gundlapalli, and National Syndromic Surveillance Program Community of Practice. 2020. "Impact of the COVID-19 Pandemic on Emergency Department Visits - United States, January 1, 2019-May 30, 2020." MMWR. Morbidity and Mortality Weekly Report 69 (23): 699-704.

\section{Tables}

Table 1: Baseline Demographics

Table 1a: Baseline Demographics of Neutropenic Patients Pre- and Post-PHEO

\begin{tabular}{|llll|}
\hline & $\begin{array}{c}\text { Year } 0^{\mathrm{a}} \\
\mathrm{n}=3276\end{array}$ & $\begin{array}{l}\text { Year } \mathbf{1}^{\mathrm{b}} \\
\mathrm{n}=2441\end{array}$ & p-value \\
\cline { 1 - 4 } Sex/Gender & & & \\
Male & $1572(48)$ & $1189(49)$ & 0.59 \\
Female & $1704(52)$ & $1252(51)$ & \\
\cline { 1 - 2 } (years) & $55.1+23.6$ & $54.7+23.7$ & 0.55 \\
\hline
\end{tabular}

Data reported at Mean + SD or $n(\%)$ unless otherwise specified

PHEO - Public Health Executive Orders from Governor's Office

ancludes the 13 months prior to Michigan's state-wide PHEO and COVID-19 mitigation efforts; March 1, 2019 to March 31, 2020

${ }^{b}$ Includes the 13 months following Michigan's state-wide PHEO and COVID-19 mitigation efforts; April 1, 2020 - April 31, 2021

Table 1b: Baseline Demographics of Febrile Neutropenic Patients vs Patients without Febrile Neutropenia Diagnosis amongst Neutropenic Patients 


\begin{tabular}{|llll|}
\hline & $\begin{array}{l}\text { No Diagnosis of Febrile } \\
\text { Neutropenia } \\
\mathrm{n}=4472\end{array}$ & $\begin{array}{l}\text { Febrile } \\
\text { Neutropenia }\end{array}$ & $p$-value \\
\hline Sex/Gender & $\mathrm{n}=1245$ & \\
\hline Male & $2145(48)$ & $616(50)$ & 0.35 \\
\hline Female & $2327(52)$ & $629(50)$ & \\
\hline Age (years) & $56.2+22.6$ & $50.3+26.6$ & $<0.0001$ \\
\hline $\begin{array}{l}\text { SpO }{ }_{2} \text { Percent on } \\
\text { Admission }\end{array}$ & $97.1+4.2$ & $96.9+3.2$ & 0.14 \\
\hline
\end{tabular}

Data reported at Mean + SD or $n(\%)$ unless otherwise specified

Table 2: Frequency of CRG Diagnosis Among Patients with Neutropenic and Febrile Neutropenia in Year 0 and Year 1. 


\begin{tabular}{|c|c|c|c|c|c|c|}
\hline & \multicolumn{3}{|c|}{ Neutropenia } & \multicolumn{3}{|c|}{$\begin{array}{l}\text { Febrile } \\
\text { Neutropenia }\end{array}$} \\
\hline & $\begin{array}{l}\text { Year } \\
0^{\mathrm{a}}\end{array}$ & $\begin{array}{l}\text { Year } \\
1^{\mathrm{b}}\end{array}$ & $p$-value & $\begin{array}{l}\text { Year } \\
0^{\mathrm{a}}\end{array}$ & $\begin{array}{l}\text { Year } \\
1^{\mathrm{b}}\end{array}$ & $p$-value \\
\hline Diagnoses & $\begin{array}{l}n= \\
3276\end{array}$ & $\begin{array}{l}n= \\
2441\end{array}$ & & $\begin{array}{l}n= \\
740\end{array}$ & $\begin{array}{l}n= \\
505\end{array}$ & \\
\hline Common infections & $\begin{array}{l}1482 \\
(45)\end{array}$ & $\begin{array}{l}974 \\
(40)\end{array}$ & $<0.0001$ & $\begin{array}{l}403 \\
(55)\end{array}$ & $\begin{array}{l}255 \\
(51)\end{array}$ & 0.17 \\
\hline Any malignancy & $\begin{array}{l}1237 \\
(38)\end{array}$ & $\begin{array}{l}833 \\
(34)\end{array}$ & 0.01 & $\begin{array}{l}276 \\
(37)\end{array}$ & $\begin{array}{l}182 \\
(36)\end{array}$ & 0.65 \\
\hline Solid malignancies & $\begin{array}{l}722 \\
(22)\end{array}$ & $\begin{array}{l}511 \\
(21)\end{array}$ & 0.32 & $\begin{array}{l}120 \\
(16)\end{array}$ & $\begin{array}{l}101 \\
(20)\end{array}$ & 0.09 \\
\hline Hematologic malignancies & $\begin{array}{l}564 \\
(17)\end{array}$ & $\begin{array}{l}357 \\
(15)\end{array}$ & 0.01 & $\begin{array}{l}165 \\
(22)\end{array}$ & $\begin{array}{l}85 \\
(17)\end{array}$ & 0.02 \\
\hline Benign neoplasms & $\begin{array}{l}147 \\
(5)\end{array}$ & $\begin{array}{l}111 \\
(5)\end{array}$ & 0.91 & $\begin{array}{l}43 \\
(6)\end{array}$ & $\begin{array}{l}17 \\
(3)\end{array}$ & 0.05 \\
\hline Non-malignant blood dyscrasias & $\begin{array}{l}1580 \\
(48)\end{array}$ & $\begin{array}{l}1213 \\
(50)\end{array}$ & 0.27 & $\begin{array}{l}315 \\
(43)\end{array}$ & $\begin{array}{l}227 \\
(45)\end{array}$ & 0.41 \\
\hline $\begin{array}{l}\text { Endocrine, nutritional, and metabolic } \\
\text { disorders }\end{array}$ & $\begin{array}{l}1485 \\
(45)\end{array}$ & $\begin{array}{l}1119 \\
(46)\end{array}$ & 0.70 & $\begin{array}{l}268 \\
(36)\end{array}$ & $\begin{array}{l}200 \\
(40)\end{array}$ & 0.23 \\
\hline $\begin{array}{l}\text { Skin, musculoskeletal, psychiatric, and } \\
\text { nervous system disorders }\end{array}$ & $\begin{array}{l}1224 \\
(37)\end{array}$ & $\begin{array}{l}870 \\
(36)\end{array}$ & 0.18 & $\begin{array}{l}211 \\
(29)\end{array}$ & $\begin{array}{l}134 \\
(27)\end{array}$ & 0.44 \\
\hline Disorders of the cardiopulmonary system & $\begin{array}{l}1639 \\
(50)\end{array}$ & $\begin{array}{l}1125 \\
(46)\end{array}$ & 0.003 & $\begin{array}{l}324 \\
(44)\end{array}$ & $\begin{array}{l}210 \\
(42)\end{array}$ & 0.44 \\
\hline $\begin{array}{l}\text { Disorders of the gastrointestinal and } \\
\text { genitourinary systems }\end{array}$ & $\begin{array}{l}1332 \\
(41)\end{array}$ & $\begin{array}{l}952 \\
(39)\end{array}$ & 0.21 & $\begin{array}{l}226 \\
(31)\end{array}$ & $\begin{array}{l}159 \\
(32)\end{array}$ & 0.72 \\
\hline COVID-19 & $6(0)$ & $\begin{array}{l}207 \\
(9)\end{array}$ & $<0.0001$ & $\begin{array}{l}0 \\
(0)\end{array}$ & $\begin{array}{l}45 \\
(9)\end{array}$ & - \\
\hline
\end{tabular}

Data reported at Mean + SD or $n(\%)$ unless otherwise specified

ancludes the 13 months prior to Michigan's state-wide PHEO and COVID-19 mitigation efforts; March 1, 2019 to March 31, 2020

${ }^{b}$ Includes the 13 months following Michigan's state-wide PHEO and COVID-19 mitigation efforts; April 1, 2020 - April 31, 2021

\section{Supplemental Table 1}

Supplemental Table 1. ICD codes categorized into Clinically Relevant Groups (CRG) 


\begin{tabular}{|ll|}
\hline Clinically Relevant Groups (CRG) & ICD 10 Code Range \\
\hline Common Infections & $\begin{array}{l}\text { A01 - B999, G00-G02, H60, H65-H70, I00-I02, J00 - J32, K35, } \\
\text { L00 - L08, N10-N12, N136.0, N39.0, R02 }\end{array}$ \\
\hline Malignant Neoplasms & C00-C97, D0-D09 \\
\hline Solid Malignancies & C00-C80, D0-D09 \\
\hline Hematologic Malignancies & C81-C96 \\
\hline Benign Neoplasms & D10-D48 \\
\hline Non Malignant Blood Dyscrasias & D50-D69, D71-D90 \\
\hline Neutropenia & D70 \\
\hline $\begin{array}{l}\text { Endocrine, nutritional and } \\
\text { metabolic diseases }\end{array}$ & E00-E90 \\
\hline $\begin{array}{l}\text { Diseases of Skin, MSK, Psychiatric, } \\
\text { and Nervous System }\end{array}$ & F00-G99, L00-M99 \\
\hline Diseases of Eye and Ears & H00-H95 \\
\hline $\begin{array}{l}\text { Disease of Cardiopulmonary } \\
\text { System }\end{array}$ & I00-J99 \\
\hline Diseases of GU/GI System & K00-K93, N00-N99 \\
\hline Covid & U07.1 \\
\hline Covid with associated codes & U07.1, Z86.16, Z20, J12.82, M35.81 \\
\hline Other & O00-Z99 \\
\hline
\end{tabular}

\section{Supplementary Files}

This is a list of supplementary files associated with this preprint. Click to download.

- SupplementaryFigure1.png 